Гуманитарные ведомости ТГПУ им. Л. Н. Толстого № 4 (36), декабрь 2020 г.

\author{
Е. Г. Курова \\ Частное образовательное учреждение высшего образования «Южный \\ университет» (Институт управления, бизнеса и права)
}

\title{
АКТУАЛЬНЫЕ ПРОБЛЕМЫ ЦЕНЗУРИРОВАНИЯ СОВРЕМЕННЫХ КИНОТЕКСТОВ
}

В статье рассматриваются основные проблемы цензурирования кинотекстов с позиции ценностной интерпретации исходного кинематографического материала. Отправной точкой исследования служит отсутствие чёткого законодательства в отношении цензуры и наличие законодательных актов, которые косвенным образом указывают на необходимость применения процедуры цензурирования в отношении кинотекстов. Отмечается необходимость введения практики ограничения выхода киноматериалов с позиции социокультурной и психологической безопасности и рассматривается ряд проблем, связанных с применением цензуры в современном кинематографе.

Ключевые слова: цензура, культурная политика, кинотекст, семиотика кино, кинопрокат, современное кино.

E. G. Kurova

Private educational institution of higher education «SOUTHERN UNIVERSITY (IMBL)»

(Rostov-on-Don, Russia)

\section{RELEVANT ISSUES OF CENSORSHIP OF MODERN FILM TEXTS}

The article deals with the main issues of censorship of film texts from the perspective of value interpretation of the original cinematic material. The starting point of the study is the lack of clear legislation on censorship and the presence of legislative acts, which indirectly indicate the need to apply the procedure of censorship in respect of film texts. The author notes that it is necessary to introduce the practice of limiting the release of film materials from the position of socio-cultural and psychological security. The article considers a number of issues related to the use of censorship in modern cinema.

Keywords: censorship, cultural policy, film text, semiotics of cinema, film distribution, modern film texts.

\section{DOI 10.22405/2304-4772-2020-1-4-75-84}

Культура информационного общества на первых этапах своего развития объявила информацию ведущей ценностью, определяющей стороны и аспекты не только коммуникации, но и всего образа жизни человека. Тиражируемой и постоянно обновляемой информации становится слишком много, но количественный рост не сопровождается возрастанием качественных характеристик текстов или улучшением способности ориентироваться в открытых информационных потоках. Более того, проблема отбора информации и опасность манипулирования посредством средств массовой коммуникации становится как никогда острой. Оправданность контроля за качеством создаваемых текстов - это вопрос, требующий ответа. В современном 
Гуманитарные ведомости ТГПУ им. Л. Н. Толстого № 4 (36), декабрь 2020 г.

общественном сознании в качестве вероятного выхода для разрешения существующих противоречий предлагается возврат к цензуре. Если говорить о последних тенденциях, то ощутимые признаки цензурирования проявляются на различных стадиях кинопроизводства (в виде самоцензуры - со стороны авторов) и отборе кинотекстов (на выходе в прокат, на стадии выдачи прокатного удостоверения - со стороны государства) [5].

Кино как средство массовой коммуникации становится не только популярным способом развлечения, но и, что более важно, способом получения информации. Создавая образы и события, кино способно воспроизводить характеры, модели поведения, закономерности отношений, используя простой язык, доступный многим. Кино предоставляет возможность рассматривать предметы, характеры и явления с разных сторон: с точки зрения режиссёра, героев фильма, позволяя также и зрителям вырабатывать собственное видение киноматериала. Нужна или не нужна цензура в кино как система ограничений так ставится главный вопрос о цензуре, при ответе на который существуют доводы «за» и «против». Многие деятели киноискусства считают цензуру ненужной, объясняя свою позицию тем, что цензура ограничивает действия режиссёров, сковывает свободу мысли и навязывает стереотипы. Большинство из них открыто выступает против цензуры и настаивает на самоцензуре, которая считается вполне возможной и осуществимой в современных социокультурных условиях.

Долгое время обществом не осознавалась потребность в цензуре, более того, сам вопрос о необходимости цензуры считался неуместным, что также было выражено и на законодательном уровне. Однако о возобновлении тенденции цензурирования кинотекстов свидетельствует ряд скандалов вокруг некоторых неоднозначных кинолент, законодательные акты, принятые на высоком государственном уровне, «запрещённые» в прокате фильмы и организационные меры Министерства культуры РФ. Проблема цензурирования является закономерным следствием Указа Президента РФ от 24 декабря 2014 г. N 808 «Об утверждении Основ государственной культурной политики» [7] и предполагает выведение ценностных, методологических и организационных критериев цензуры.

Согласно Конституции Российской Федерации и Закону о СМИ, цензура запрещена, и гражданам гарантируется свобода массовой информации [1; 3]. Следовательно, возникает вопрос о необходимости и возможности возвращения цензуры и как социокультурной нормы, и как реально действующей процедуры частичного ограничения кинотекстов - независимо от времени их создания. Проблема данного исследования - необходимость, возможности и рамки цензуры в сфере кинотекстов (или процедур, замещающих цензуру) в современных правовых и социокультурных условиях.

В той или иной форме цензура необходима в силу наличествования открытой информации, относящейся к антикультуре и способной отрицательно сказываться на моральном и психологическом аспекте жизнедеятельности человека. Для самостоятельного самоограничения (со стороны авторов или 
Гуманитарные ведомости ТГПУ им. Л. Н. Толстого № 4 (36), декабрь 2020 г.

зрителей) подобной информации необходимо сформированное критическое мышление, которое в современной культуре не декларируется как ценность, не говоря уже о том, что сами ценности, в соответствии с которыми должен происходить отбор, достаточно размыты. Установление любой единой системы ценностей в мультикультурном пространстве - это глобальная и сложная проблема, но в рамках вопроса о цензуре обычно исходят из установления того, что составляет так называемую антикультуру и приводит к дегуманизации сознания. В силу этого исходным пунктом в решении проблемы ограничения информации является проблема определения культурных ценностей, в соответствии с которыми должен происходить отбор.

Мотивы введения цензуры в целом и в сфере кино, в частности, затрагивают, прежде всего, вопросы сохранения культуры как механизма обеспечения целостности и развития как личности, так и общества. В самой крайней точке введение цензуры обусловлено необходимостью сохранения психического здоровья зрителей, которое, помимо прочих факторов, зависит и от восприятия киноматериала. Соответственно, подход к отбору кинотекстов продиктован необходимостью защиты психики и сохранения культуры. Исключение здесь составляют документальные и обучающие фильмы, необходимые для конкретной профессиональной деятельности (например, документальные фильмы с подробным разбором авиакатастроф - для лётчиков, инженеров и т.д. [6]).

Для цензурирования в сфере кино наиболее значимыми, в соответствии с текущей ситуацией в сфере кинематографа, являются ограничения этического и эстетического порядка. Цензура в кино осуществляется с ценностных и эстетических позиций, которые передают отношение к кинотексту как явлению культуры и отношения внутри социальных групп. Как отмечает М. В. Зеленов, цензура не является привилегией исключительно государства, но может осуществляться и другими социальными институтами, включая церковь [2].

Возвращение практик цензурирования в современной России требует серьёзной идеологической обоснованности и безусловной поддержки на государственном уровне. Но самым главным вопросом остаётся вопрос об идеологических критериях цензуры в условиях общества, позиционирующего себя как демократическое. Свобода совести и плюрализм мнений, выдвигаемые как ценности, не конкретизированы с точки зрения возможности антигуманистических влияний и распространения процессов дегуманизации.

Проблема определения социокультурных ориентиров, необходимых для ограничения кинотекстов должна решаться как на законодательном уровне, так и внутри профессиональных сообществ. Без наличия более или менее устойчивой законодательной базы, которая включает в себя запрещающие, управомочивающие, охранительные и регулятивные правовые нормы, невозможно проводить анализ и рецензирование фильма с позиции цензуры. Более того, любые притязания на цензуру могут быть расценены как не имеющие под собой законных оснований.

На данном этапе современное российское законодательство в вопросе о 
Гуманитарные ведомости ТГПУ им. Л. Н. Толстого № 4 (36), декабрь 2020 г.

цензуре в СМИ входит в фактическое противоречие, которое не находит должного разрешения на законодательном уровне. Проблемы цензуры в кино остаются площадкой для споров деятелей и коммерсантов от киноискусства, которые оказываются заинтересованы вопросами цензуры не только с позиции развития творчества, но и с позиции получения прибыли. Соответственно, должен быть ряд законодательных актов, к которым можно апеллировать при рассмотрении вопроса допуска или недопуска фильма в прокат. Тем более, что законодательные акты, которые подразумевают введение цензуры, уже постепенно появляются в ходе текущего законотворческого процесса [5; 7-9].

Недостатком всех законодательных актов, подразумевающих цензуру, является отсутствие каких-либо определённых формулировок тех нравственных принципов и ограничений, которые выносятся за основные критерии отбора: например, не устанавливаются чёткие определения и характеристики «насилия», «порнографии», «экстремизма», «женоненавистничества» и т.д., репрезентируемых в рамках кинотекста именно как деструктивный материал. В применении терминологии морального и эстетического порядка к цензурному анализу фильмов может быть полезным сотрудничество с профессиональными сообществами деятелей киноискусства, которые владеют навыками представления разного контента на экране и знают особенности восприятия кинотекстов.

С точки зрения ограничений, уже имевших место, за краем цензуры остаются такие идейные комплексы как дискриминация взрослых, пропаганды свободы как вседозволенности, культ потребления, разрушение ценностей традиционной семьи. «Отсев» фильмов по данным критериям не осуществляется, а вышеупомянутые темы становятся «предметом умолчания». Например, в Норвегии, по причине трактовки эпизодов фильма как дискриминирующих социальный статус взрослого, был запрещён фильм «Инопланетянин» (1982; реж. - Ст. Спилберг) - в то время как отечественный мультсериал «Маша и Медведь» $(2009$ - 2019) в России не рассматривается с точки зрения трансформации ценностной иерархии «взрослый - ребёнок».

Самым актуальным вопросом в отношении цензуры становится вопрос о судьбе кино, тяготеющего к реализму, в котором некоторый «запрещённый» контент является художественным приёмом отображения действительности. Отрицая неприглядные аспекты действительности, режиссёры рискуют уйти в иллюзорность и даже фантастичность: так, например, в фильме «Мёртвый снег - 2» (2014) активными действующими персонажами становятся нацисты-зомби, что повлекло за собой обвинения в кощунстве со стороны кинокритиков. Вольное обращение с серьёзным историческим контекстом, затрагивающим героическое историческое прошлое, - это проблема, которая не снимается даже переводом исторической тематики в фантастический жанр (как адаптированный материал для современной молодёжи). Например, разрешённые к показу фильмы «Мы из будущего» (2008) и «Мы из будущего2» (2010) делают акцент на фантастичности происходящих с героями событий и не объясняют сущность и причины заявленной в фильме идеи патриотизма: 
Гуманитарные ведомости ТГПУ им. Л. Н. Толстого № 4 (36), декабрь 2020 г.

герои последовательно умирают один за другим в ситуациях, в которых можно выжить и победить врага, и возвращаются в будущее.

Существуют достаточно удачные в реалистическом отношении фильмы, которые содержат темы, сцены и язык запрещённого контента, но не являются пропагандой содержания, запрещённого законодательством РФ. Таковые фильмы не всегда принадлежат реалистическому направлению непосредственно, но своей сюжетной линией и смысловой направленностью опровергают асоциальный образ жизни как вариант решения проблем («Монстр» (2003), «Малхоланд Драйв» (2001), серил «Игра престолов» (20112019)).

Отрицательный и негативный контент может составлять необходимое содержание фильма, но не должен искажать восприятие в сторону своей самоценности, оторванности от причинно-следственных связей, его обусловливающих. Кино обладает хорошим арсеналом возможностей транслировать идеологию, способно утверждать и разрушать социокультурные ценности, и поэтому негативное содержание фильма не должно вызывать эффекта восприятия увиденного как нормы. Будучи познавательной практикой, кино способно воспроизводить то, что становится узнаваемым зрителями как события их личной биографии, исторический материал и моменты повседневности. Описанное свойство характеризует фильмы реалистического толка, которые пользуется большой популярностью и поддерживаются различными кинематографическими премиями и наградами: например, фильмы-лауреаты премии «Оскар» в плане репрезентации реальности относятся в большей степени к кинематографу реализма. Также посредством кино можно создавать условия, невозможные в реальном мире и, минуя условности, препятствующие пониманию основных идей фильма, направлять внимание зрителя на том содержании, которое режиссёр хочет выделить как основное.

За рамками наметившейся цензуры часто остаётся проблема фактического несоответствия содержания фильмов с той исторической, бытовой, психологической и социокультурной реальностью, которую они репрезентируют. Если для советской цензуры проблема несоответствия и недостоверности была критерием отказа в прокате, то современная цензура обращает внимание только на грубейшие искажения в трактовке фактов исторического прошлого. Среди зрителей, знающих фактический и исторический материал, уже давно возникает недовольство качеством современных фильмов о Великой Отечественной войне, поэтому предпочтения отдаются старым советским кинолентам, скрупулёзно выдерживающим фактический материал.

Задача кинематографа - не передача во всех подробностях отрицательных сторон жизненного бытия человека и не подавление мыслительного процесса через восприятие шоковых или «запрещённых» сцен. Кино призвано акцентировать внимание на том, что способно вывести зрителя в область критического отношения к реальности, Конечно, речь также идёт о 
Гуманитарные ведомости ТГПУ им. Л. Н. Толстого № 4 (36), декабрь 2020 г.

соотношении тематических и содержательных эпизодов кино и процентной доли «слишком реалистичной реальности» в общей доли демонстрируемых фильмов.

Однако любая возникающая возможность введения цензуры влечёт за собой проблему свободы самовыражения художника и проблему свободы выбора у человека, воспринимающего произведения искусства. Нельзя сказать, что отказ от цензуры снимает общую проблему свободы, которая в связи с отсутствием ограничений может пониматься как вседозволенность. Не решает проблему свободы также и самоцензура как единственный метод контроля и отбора информации, так как утверждение самоцензуры требует формирования и пропаганды ответственного отношения художника к своим произведениям. В современных социокультурных условиях девальвации ценностей становится проблематичным ввести самоцензуру как общественную норму. Установление самоцензуры как ценности в обществе предполагает формирование ряда компетенций, которые выходят далеко за рамки узкопрофессиональных.

Также весьма противоречивым решением является установление точного возрастного ценза для кинолент. Остаётся нерешённым вопрос о том, по каким критериям возможно рекомендовать фильм к просмотру совершеннолетним, подросткам и детям, по каким критериям можно судить о наступлении нравственной и эстетической зрелости? Опять-таки установление разных возрастных градаций для рекомендации к просмотру может послужить поводом к просмотру лицами, чей возраст моложе рекомендованного. Таким образом, установление возрастного ценза может послужить и маркетинговым ходом, но уже не со стороны организаций, осуществляющих цензуру, а со стороны создателей фильмов.

Помимо введения ограничивающих критериев, сложной проблемой является поиск методологической базы для анализа исходного кинематографического материала, претендующего на выход в прокат. Необходимые методологические основания для цензурирования кинотекстов требуют выработки подходов для анализа с точки зрения специфики самих фильмов - их жанровой, стилистической, образной и сюжетной соотнесённости. Преимуществом здесь обладает семиотический метод анализа коннотативных и денотативных значений в фильмах, приемлемости использования некоторых выразительных средств и приёмов в кино с точки зрения целевой возрастной аудитории. Семиотическая теория в сотрудничестве с теорией визуальной коммуникации ставит вопросы о том, каким образом значение производится, транслируется и интерпретируется посредством сообщений, которые являются, прежде всего, визуальными [13, p. 26]. В рамках семиотических исследований накоплен богатейший исследовательский опыт, который позволяет посредством скрупулёзного анализа кадров и взаимосвязи кадров [4], сопоставления звукового ряда, рассмотрения приёмов и техник монтажных решений [10] и т.д. делать выводы об идейном содержании фильма. Здесь особое значение приобретают семиотические исследования зарубежных киноведов [11-14], которые стараются придать семиотическим 
Гуманитарные ведомости ТГПУ им. Л. Н. Толстого № 4 (36), декабрь 2020 г.

исследованиям кино большей ясности и основательности. Благодаря категориальному аппарату семиотики кино [14], обогащённому понятиями, заимствованными из лингвистики, теории визуальной коммуникации, эстетики, теории и истории кинематографа и т.д., становится возможным проводить анализ кинотекстов не только в плане формирования определённого значения, которое может находиться на поверхности или только подразумеваться, но и с учётом различных граней исследования.

Вышеупомянутые проблемы цензурирования современных кинотекстов требуют решения как проблемы идеологические (определение шкалы нравственных и эстетических оценок), методологические (разработка методов анализа) и организационные (разработка организационных мер и определение системы ведомств). Важность решения проблем цензурирования определяется необходимостью успешной социализации личности и уменьшения рисков аномии и девиантного поведения. Цензура, среди прочих других социальных институтов, выработанных в истории культуры, помогает утверждать этические и эстетические ценности, имеющие первостепенное значение для человека и общества.

\section{Лumepamypa}

1. Закон РФ от 27.12.1991 N 2124-1 (ред. от 01.03.2020) «О средствах массовой информации»). Статья 3. Недопустимость цензуры [Электронный ресурс] // КонсультантПлюс. М., 1997-2020. URL: http://www.consultant.ru/document/cons doc LAW_1511/ (дата обращения: 05.05.2020).

2. Зеленов М. В. Цензура: подходы к определению понятия // Ленинградский юридический журнал. 2013. № 1 (31). С. 94-103.

3. Конституция Российской Федерации : принята всенародным голосованием 12 декабря 1993 г. с изменениями, одобренными в ходе общенародного голосования 07 июля 2020 г. [Электронный ресурс] // КонсультантПлюс. M., 1997-2020. URL: http://www.consultant.ru/document/cons doc LAW 28399/ (дата обращения: 20.07.2020).

4. Лотман Ю. М. Семиотика кино и проблемы киноэстетики [Электронный pecypc] // Lib.ru: Библиотека Максима Мошкова. URL: http://lib.ru/CINEMA/kinolit/LOTMAN/kinoestetika.txt $\quad$ (дата обращения: 04.03.2019).

5. Постановление Правительства РФ от 27.02.2016 N 143 (ред. от 21.12.2016) «Об утверждении Правил выдачи, отказа в выдаче и отзыва прокатного удостоверения на фильм и Правил ведения Государственного регистра фильмов» [Электронный ресурс] // КонсультантПлюс. М., 1997-2020. URL: $\quad$ http://www.consultant.ru/document/cons doc LAW 194707/ (дата обращения: 05.05.2020).

6. Расследование авиакатастроф [Электронный ресурс] // National 
Гуманитарные ведомости ТГПУ им. Л. Н. Толстого № 4 (36), декабрь 2020 г.

Geographic : офиц. сайт телеканала в России : [сайт]. [2020]. URL: https://www.natgeotv.com/ru/shows/natgeo/air-crash-investigation (дата обращения: 04.03.2020).

7. Указ Президента Российской Федерации от 24 декабря 2014 г. N 808 «Об утверждении Основ государственной культурной политики» [Электронный ресурс] // КонсультантПлюс. M., 1997-2020. URL: http://www.consultant.ru/document/cons doc LAW_172706/ (дата обращения: 04.03.2020).

8. Федеральный закон «О внесении изменений в статью 242.1 Уголовного кодекса Российской Федерации в целях противодействия обороту порнографической продукции с использованием несовершеннолетних и (или) среди несовершеннолетних и статью 151 Уголовно-процессуального кодекса Российской Федерации» от 23.06.2016 N 199-Ф3 (последняя редакция). [Электронный ресурс] // КонсультантПлюс. M., 1997-2020. URL: http://www.consultant.ru/document/cons doc_LAW_200015/ (дата обращения: 04.03.2020).

9. Федеральный закон «О государственной поддержке кинематографии Российской Федерации» от 22.08.1996 N 126-Ф3 (последняя редакция) [Электронный ресурс] // КонсультантПлюс. M., 1997-2020. URL: http://www.consultant.ru/document/cons_doc_LAW_11454/ (дата обращения: 04.03.2020).

10. Эйзенштейн C. М. Монтаж (1938) [Электронный ресурс] // Lib.ru: Библиотека Максима Мошкова. URL: http://lib.ru/CINEMA/kinolit/EJZENSHTEJN/s_montazh_1938.txt обращения: 01.06.2019).

11. Danesi M. Messages, Signs, and Meanings: A Basic Textbook in Semiotics and Communication. Toronto ; Ontario: Canadian Scholars Press, 2004. P. 393.

12. Metz C. Film language: A semiotics of the cinema. Chicago: University of Chicago Press, 1991. P. 268.

13. Moriarty S. E. The Symbiotics of Semiotics and Visual Communication // Journal of Visual Literacy. 2002. Vol. 22, No 1. P. 19-28.

14. Stam R., Burgoyne R., Flitterman-Lewis S. New Vocabularies in Film Semiotics: Structuralism, post-structuralism and beyond. London ; New York : Routledge, Taylor \& Francis e-Library, 2005. P. 246.

\section{Refrences}

1. Zakon RF ot 27.12.1991 N 2124-1 (red. ot 01.03.2020) «O sredstvakh massovoy informatsii»). Stat'ya 3. Nedopustimost' tsenzury [Law of the Russian Federation of 27.12.1991 N 2124-1 (revised from 01.03.2020) "On the Mass Media"). Article 3. Inadmissibility of censorship]. Konsul'tantPlyus. Moscow, 1997-2020. URL: http://www.consultant.ru/document/cons_doc_LAW_1511/ (accessed: 05 May 2020). [In Russian] 
Гуманитарные ведомости ТГПУ им. Л. Н. Толстого № 4 (36), декабрь 2020 г.

2. Zelenov M. V. Tsenzura: podkhody $\mathrm{k}$ opredeleniyu ponyatiya [Censorship: Approaches to the Definition]. Leningradskiy yuridicheskiy zhurnal. 2013. Issue 1(31). Pp. 94-103. [In Russian]

3. Konstitutsiya Rossiyskoy Federatsii : prinyata vsenarodnym golosovaniyem 12 dekabrya 1993 g. s izmeneniyami, odobrennymi v khode obshchenarodnogo golosovaniya 07 iyulya 2020 g [Constitution of the Russian Federation: adopted by popular vote on December 12, 1993, with amendments approved by popular vote on July 7, 2020.]. Konsul'tantPlyus. Moscow, 1997-2020. URL: http://www.consultant.ru/document/cons_doc_LAW_28399/ (accessed: 05 July 2020). [In Russian]

4. Lotman Yu. M. Semiotika kino i problemy kinoestetiki [Semiotics of cinema and problems of cinema aesthetics]. URL: http://lib.ru/CINEMA/kinolit/LOTMAN/kinoestetika.txt (accessed: 4. March 2019). [In Russian]

5. Postanovleniye Pravitel'stva RF ot 27.02.2016 N 143 (red. ot 21.12.2016) «Ob utverzhdenii Pravil vydachi, otkaza v vydache i otzyva prokatnogo udostovereniya na fil'm i Pravil vedeniya Gosudarstvennogo registra fil'mov» [Decree of the Government of the Russian Federation of February 27, 2016 N 143 (as amended on December 21, 2016) "On approval of the Rules for the issuance, refusal to issue and revoke the distribution certificate for a film and the Rules for maintaining the State Register of Films"]. Konsul'tantPlyus. Moscow, 1997-2020. [In Russian]

6. Rassledovaniye aviakatastrof [Air Crash Investigation]. National Geographic v Rossii [National Geographic in Russia]: 2020. URL: https://www.natgeotv.com/ru/shows/natgeo/air-crash-investigation $\quad$ (accessed: 4 March 2020). [In Russian]

7. Ukaz Prezidenta Rossiyskoy Federatsii ot 24 dekabrya 2014 g. N 808 «Ob utverzhdenii Osnov gosudarstvennoy kul'turnoy politiki» [Decree of the President of the Russian Federation of December 24, 2014 N 808 "On Approval of the Fundamentals of State Cultural Policy"]. Konsul'tantPlyus. Moscow, 1997-2020. URL: http://www.consultant.ru/document/cons doc LAW 172706/ (accessed: 04 March 2020). [In Russian]

8. Federal'nyy zakon «O vnesenii izmeneniy v stat'yu 242.1 Ugolovnogo kodeksa Rossiyskoy Federatsii $\mathrm{v}$ tselyakh protivodeystviya oborotu pornograficheskoy produktsii $\mathrm{s}$ ispol'zovaniyem nesovershennoletnikh i (ili) sredi nesovershennoletnikh i stat'yu 151 Ugolovno-protsessual'nogo kodeksa Rossiyskoy Federatsii» ot 23.06.2016 N 199-FZ (poslednyaya redaktsiya) [Federal Law "On Amendments to Article 242.1 of the Criminal Code of the Russian Federation in order to counteract the circulation of pornographic products featuring underage children and (or) among minors and Article 151 of the Criminal Procedure Code of the Russian Federation" dated 23.06.2016 N 199-FZ (latest edition)]. Konsul'tantPlyus. Moscow, 1997-2020. URL: http://www.consultant.ru/document/cons doc LAW 200015/ (accessed: 04 March 2020). [In Russian] 
Гуманитарные ведомости ТГПУ им. Л. Н. Толстого № 4 (36), декабрь 2020 г.

9. Federal'nyy zakon «O gosudarstvennoy podderzhke kinematografii Rossiyskoy Federatsii» ot 22.08.1996 N 126-FZ (poslednyaya redaktsiya) [Federal Law "On State Support of Cinematography of the Russian Federation" of 08.22.1996 $\mathrm{N}$ 126-FZ (last edition)]. Konsul'tantPlyus. Moscow, 1997-2020. URL: http://www.consultant.ru/document/cons_doc_LAW_11454/ (accessed: 04 March 2020). [In Russian]

10. Eisenstein S. M. Montazh [Montage]. 1938. URL: http://lib.ru/CINEMA/kinolit/EJZENSHTEJN/s montazh 1938.txt (accessed: 1 June 2019).

11. Danesi M. Messages, Signs, and Meanings: A Basic Textbook in Semiotics and Communication. Toronto, Ontario: Canadian Scholars Press, 2004. $393 \mathrm{p}$.

12. Metz C. Film language: A semiotics of the cinema. Chicago: University of Chicago Press, 1991. 268 p.

13. Moriarty S. E. The Symbiotics of Semiotics and Visual Communication. Journal of Visual Literacy. 2002. Vol. 22, No 1. Pp.19-28.

14. Stam R., Burgoyne R., Flitterman-Lewis S. New Vocabularies in Film Semiotics: Structuralism, post-structuralism and beyond. London, NY: Routledge, Taylor \& Francis e-Library, 2005. 246 p.

Статья поступила в редакцию 23.07.2020 Статья допущена к публикачии 14.12.2020

The article was received by the editorial staff 23.07.2020

The article is approved for publication 14.12.2020 